\title{
Influence of the initial hydrostatic pressure on contact area coefficient under drainage condition
}

\author{
Chaoqun Feng ${ }^{1}$, Pei Zhang ${ }^{2,3}$, Chengshun $\mathrm{Xu}^{1, *}$, Xiuli $\mathrm{Du}^{1}$ \\ ${ }^{1}$ The Key Laboratory of Urban Security and Disaster Engineering of Ministry of \\ Education, Beijing University of Technology, 100124 Beijing, China \\ ${ }^{2}$ School of Civil and Transportation Engineering, Beijing University of Civil \\ Engineering and Architecture, 102616 Beijing, China \\ ${ }^{3}$ Department of Civil and Environmental Engineering, The Hong Kong Polytechnic \\ University, Hung Hom, Kowloon, Hong Kong, China
}

\begin{abstract}
The expression of effective stress proposed by Terzaghi has always been questioned. Many correction formulas are modification of pore pressure term. The pore pressure factor is related to porosity, contact area and other factors. When the particles are in point contact, the expression of the effective stress is that proposed by Terzaghi, while for the surface contact particles, the actual effective stress increases the stress produced by pore pressure passing through the contact surface based on the Terzaghi effective stress. There are many factors that affect the development of contact area and pore pressure, therefore, a series of the drained triaxial tests were carried out on four groups of sand samples with different initial hydrostatic pressures to study the influence of different initial hydrostatic pressures on the effective stress due to the term of contact area $(\sigma \alpha)$. The test results show that the shear strength is increases with the initial hydrostatic pressure under the same effective confining pressure, which indirectly indicates that the initial hydrostatic pressure increases the contact area stress.
\end{abstract}

\section{Introduction}

Terzaghi effective stress principle has been controversial since it was proposed, especially the approximate calculation of effective stress. Many researchers have put forward different effective stress expressions from different aspects. The modifications are mainly for the pore pressure term and these expressions can be written in the form of equation (1), where $\sigma^{\prime}$ is the effective stress, $\sigma$ is the totle stress, $p$ is the pore pressure, and $\eta$ is the pore pressure factor. In the calculation expression of Terzaghi effective stress $\eta=1$, other expressions for $\eta$ are shown in the table 1 .

$$
\sigma^{\prime}=\sigma-\eta p
$$

It was pointed out by $\mathrm{Du}$ et.al. ${ }^{[17]}$ that the effective stress is the link between the measurable load effects such as the strength and deformation and external load. In addition, the concepts of strength related effective stress and deformation related effective stress were proposed, and the expressions of effective stress related to strength and deformation were derived respectively. It was regarded that in the expression of strength related effective stress, the pore pressure factor is related to the particle contact coefficient and the expression is given as following:

$$
\sigma^{\prime}=\sigma-(1-\alpha) p=\sigma-p+\alpha_{c}(1-n) p
$$

Where, $\alpha_{c}$ is the ratio of contact area on the section, $n$ is the porosity of saturated soil. When the contact area of
Table 1. Expressions for pore pressure factor $\eta$ ( According to the literature ${ }^{[1-3]}$ )

\begin{tabular}{|c|c|}
\hline$\eta$ & Researchers \\
\hline 1 & $\begin{array}{c}\text { Terzaghi }^{[4,5]}, \mathrm{Skempton}^{[6]}, \\
\mathrm{Oka}^{[7]}, \mathrm{Li}^{[8,9]}, \\
\mathrm{Shao}^{[10]}, \mathrm{Lu}^{[11]}\end{array}$ \\
\hline$n$ & Biot $^{[12]}$
\end{tabular}

\footnotetext{
${ }^{*}$ Corresponding author: xuchengshun@bjut.edu.cn
} 
particles is 0 , in other word, it is point contact mode between soil particles, equation (2) is the calculation formula of Terzaghi effective stress. When the contact mode between particles is surface contact, the effective stress is composed of two parts: the effective stress proposed by Terzaghi and the effective stress term produced by pore pressure acting on the contact surface.

Strictly speaking, the contact area is influenced by the initial hydrostatic pressure $\left(\sigma_{0}\right)$, effective consolidation pressure, porosity and overconsolidation ratio, etc. The larger the initial hydrostatic pressure and consolidation pressure are, the larger the particle contact area is, and the larger the contact area is, the smaller the area of pore pressure acting on soil particles is, when the porosity of saturated soil remains constant. For general geotechnical engineering, because the contact area coefficient is very small, its influence can be ignored. However, for the deep-sea geotechnical engineering, the influence of contact area can not be ignored and more research is needed.

However, the effect of $\alpha p$ on effective stress and strength is very complex. On the one hand, there are many factors affecting the contact area, and there should be some functional relationship (linear or nonlinear) between the contact area coefficient and the initial hydrostatic pressure and other factors, that is, $\alpha=\alpha\left(\sigma_{0}, \sigma^{\prime} \ldots\right)$. On the other hand, there are many factors influencing the development mode of pore water pressure, such as pore water pressure ratio, site boundary conditions and so on. Especially, when the dynamic characteristics of saturated sand are studied in laboratory tests, the back pressure method is used to saturate the sand samples. In fact, the back pressure represents the initial hydrostatic pressure of the saturated soil layer in the site. It is generally believed that the back pressure has no effect on the liquefaction characteristics of saturated soil, so it is not specified in the standard for geotechnical test methods. However, some researchers ${ }^{[24]}$ found that the initial hydrostatic pressure has a great influence on the development of pore pressure and the shear strength of saturated sand under undrained conditions. The effective stress calculation formula should consider the factors affecting $\alpha$, because of the complexity of the contact area and pore pressure. Thus it is more rigorous to rewrite the equation (2) as following:

$$
\sigma^{\prime}=\sigma-p+\sigma_{\alpha}
$$

Where, $\sigma_{\alpha}$ is the effective stress term related with the contact area, porosity and the pore pressure, in addition, it is a simple expression after considering their influence factors.

There are many factors that have influence on $\sigma_{\alpha}$, however, there is still a lack of research on them, and it is also very difficult to measure $\alpha_{c}$ and to quantitatively analyze the influence of various factors on the contact area coefficient. As is known to all, under drainge conditions, there is no pore pressure produced, thus, the initial hydrostatic pressure will not affect the shear strength of saturated soil by affecting the development of pore pressure. However, according to the above analysis and equation (3), the initial hydrostatic pressure will affect the shear strength by affecting $\sigma_{\alpha}$,
In this paper, drained triaxial test under different consolidation pressure and different initial hydrostatic pressure were carried out. By analyzing the shear strength under different conditions, the influence of initial hydrostatic pressure on $\sigma_{\alpha}$ is qualitatively analyzed.

\section{Test and result analysis}

\subsection{Sample preparation and test design}

The back pressure saturation, isotropic consolidation and effective stress strength properties are well controlled and measured using GDS triaxial apparatus system. It provided automatic control of the applied cell- and backpressures to an accuracy of $1 \mathrm{kPa}$, along with measurement of the specimen volume change response to an accuracy of 10-3 ml. Figure (1) shows a typical sample of the conventional triaxial test. The major and minor principal stresses are denoted as $\sigma_{1}{ }^{\prime}$ and $\sigma_{3}^{\prime}$, respectively. The relationship among them are $\sigma_{1}^{\prime}>\sigma_{3}^{\prime}=$ $\sigma_{2}^{\prime}$. The Fujian standard sand is used. In order to avoid the impact of particle breakage on the mechanical properties of the sand, the sample is only used once in the test and is not reused. In the process of sample loading, the diameter and height of the samples will be strictly controlled. The diameter and height of all samples are well controlled to be $50.8 \mathrm{~mm}$ and 106.5 $\mathrm{mm}$, and the mass of wet sand in saturated sample is $456.6 \mathrm{~g}$ with the precision of $\pm 0.02 \mathrm{~g}$.

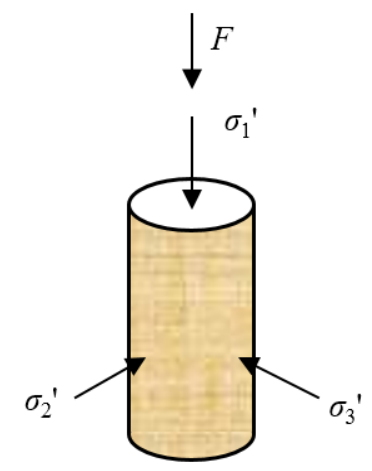

Fig.1. The stress condition of sample in conventional triaxial test.

The consolidation drainage test (CD) is used and in the process of saturation, axial loading was conducted at an axial strain rate of $0.1 \mathrm{~mm} / \mathrm{min}$ under a drained condition, allowing excess pore water pressures to dissipate in theory, and the back pressure is controlled to reach the predetermined value, and remains constant in the consolidation and loading stages. The $\mathrm{B}$ value of all samples is above $98 \%$, which satisfies the requirement of saturation. The test conditions are shown in table 2 .

Table 2. Samples conditions in conventional triaxial tests of saturated sands.

\begin{tabular}{|c|c|c|c|}
\hline$\sigma_{3}{ }^{\prime}$ & Test No. & $\sigma_{0}(\mathrm{kPa})$ & Test type \\
\hline \multirow{2}{*}{100} & 1 & 300 & $\mathrm{CD}$ \\
\cline { 2 - 4 } & 2 & 500 & $\mathrm{CD}$ \\
\hline
\end{tabular}




\begin{tabular}{|c|c|c|c|}
\hline \multirow{3}{*}{} & 3 & 700 & $\mathrm{CD}$ \\
\cline { 2 - 4 } & 4 & 900 & $\mathrm{CD}$ \\
\hline \multirow{3}{*}{200} & 5 & 300 & $\mathrm{CD}$ \\
\cline { 2 - 4 } & 6 & 500 & $\mathrm{CD}$ \\
\cline { 2 - 4 } & 7 & 700 & $\mathrm{CD}$ \\
\cline { 2 - 4 } & 8 & 900 & $\mathrm{CD}$ \\
\hline \multirow{3}{*}{300} & 9 & 300 & $\mathrm{CD}$ \\
\cline { 2 - 4 } & 10 & 500 & $\mathrm{CD}$ \\
\cline { 2 - 4 } & 11 & 700 & $\mathrm{CD}$ \\
\cline { 2 - 4 } & 12 & 900 & $\mathrm{CD}$ \\
\hline \multirow{3}{*}{400} & 13 & 300 & $\mathrm{CD}$ \\
\cline { 2 - 4 } & 14 & 500 & $\mathrm{CD}$ \\
\cline { 2 - 4 } & 15 & 700 & $\mathrm{CD}$ \\
\hline
\end{tabular}

\subsection{Test results and analysis}

In the conventional triaxial compression test, the generalized shear stress is $q=\sigma_{1}-\sigma_{3}$. The relathionships between the the generalized shear stress and axial strain under different initial hydrostatic pressures and effective confining pressures are given in figure 2 . It should be noted that, when the effective confining pressure $\left(\sigma_{3}^{\prime}\right)$ is $400 \mathrm{kPa}$ and the back pressure $\left(\sigma_{0}\right)$ is $900 \mathrm{kpa}$, the test instrument reaches the maximum range, thus the results can not be obtained.

If there exist peak point in stress-strain relationship, the failure is thought to occur at the peak value of deviator stress. When the stress-strain relationship has no peak value, the failure takes place at strain of $15 \%{ }^{[25]}$. According to the figure 2, the drained shear strength is taken as the deviator stress at the maximum value. It can be seen from the figure 2 that the shear strength of soil is increasing with effective confining pressures. Under the same effective confining pressure, the shear strength of soil is increasing with the initial hydrostatic pressure. Taking the effective confining pressure of $100 \mathrm{kPa}$ as an example, when the initial hydrostatic pressure is $300 \mathrm{kPa}$, the maximum shear strength is $280 \mathrm{kPa}$ and when the initial hydrostatic pressure increases to $900 \mathrm{kPa}$, the maximum shear strength is about $310 \mathrm{kPa}$.

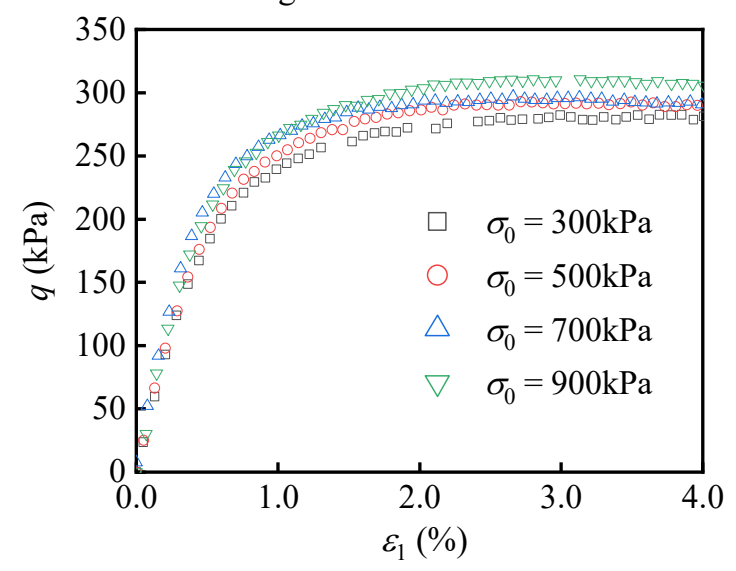

(a) $\sigma_{3}{ }^{\prime}=100 \mathrm{kPa}$

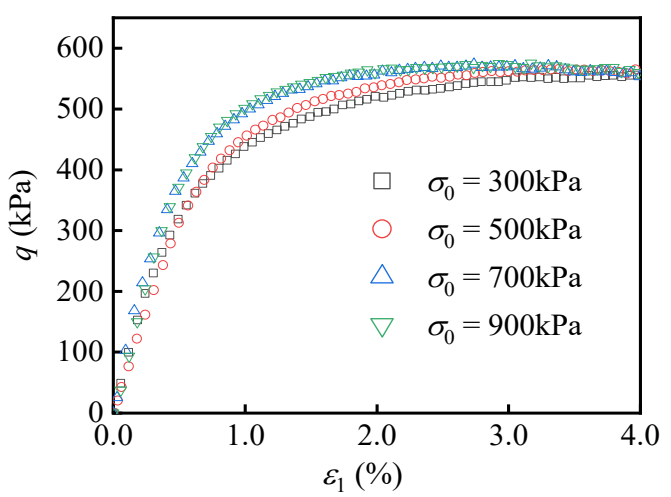

(b) $\sigma_{3}{ }^{\prime}=200 \mathrm{kPa}$

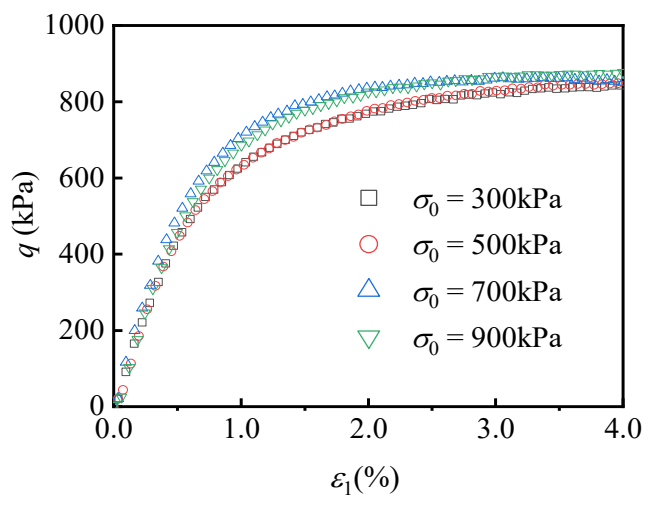

(c) $\sigma_{3}{ }^{\prime}=300 \mathrm{kPa}$

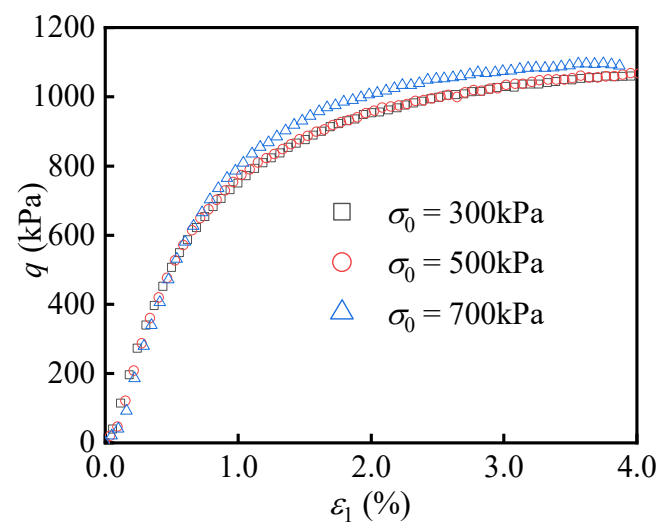

(d) $\sigma_{3}{ }^{\prime}=400 \mathrm{kPa}$

Fig.2. CD test results under four different confining pressures.

The shear strength of specimens under different initial hydrostatic pressure and consolidation pressure is depicted in figure 3 . Although the influence of initial hydrostatic pressure on shear strength is small, the four groups of test data have a unified rule, which can eliminate the possibility of test error. It can be concluded that under the same consolidation pressure and porosity, the effect of initial static shear stress on the contact area has an impact on the shear strength of sand. 


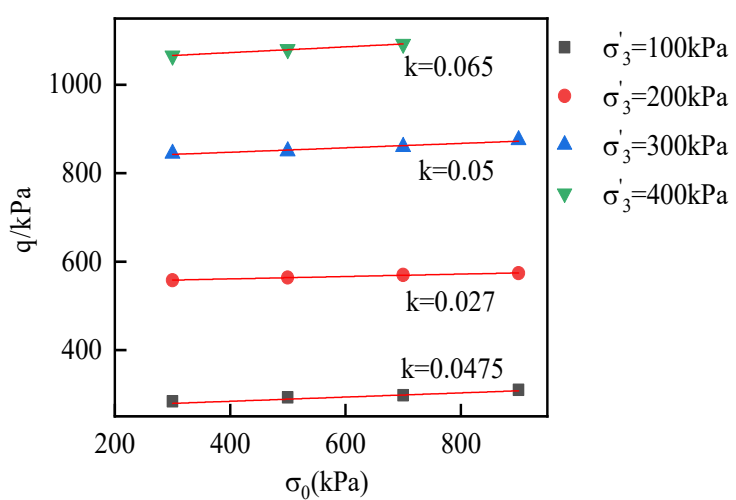

Fig.3. Effect of different initial hydrostatic pressure on drained shear strength of soil

\section{Conclusion}

In this paper, the effective stress term caused by contact area is discussed $\alpha p$, which is directly related to the contact area coefficient and pore pressure. The contact area coefficient is directly related to the contact area ratio and porosity, and the factors that affect the contact area ratio and porosity also directly affect the contact area coefficient; In addition, the factors that affect the development of pore water pressure also directly affect the development of pore water pressure $\alpha p$. Due to the complexity of the above factors, this paper simplifies the term to $\sigma_{\alpha}$. The influence of initial hydrostatic pressure on shear strength of saturated sand is obtained by triaxial drainage test, which is verified by lateral test $\sigma_{\alpha}$ The effect of term on shear strength. Under the condition of drainage, the influence of initial hydrostatic pressure on shear strength is small, but it still presents regularity, that is, the greater the initial hydrostatic pressure is, the stronger the shear strength is.

The influence of initial hydrostatic pressure on the shear strength of sand under drainage condition is studied in this paper, and the results indirectly show that $\sigma_{\alpha}$ should be considered in the calculation of effective stress, and the initial hydrostatic pressure theoretically has an influence on the contact area of particles. Therefore, the tests also give the influence law of initial hydrostatic pressure on $\sigma_{\alpha}$. However, a lot of researches are needed to verify the equation (3). In this paper only a feasible research method are provided. In addition, further researches are needed to study the influencing factors of contact area, so as to adapt to the development trend of ultra-deep engineering.

\section{Acknowledgments}

This research was supported by National Natural Science Foundation of China (51722801). The supports from the above organizations are gratefully acknowledged.

\section{References}

1. Boer R.D., Lade P.V. (1997) The concept of effective stress for soil, concrete and rock. Geotechnique., 47: 61-78.

2. Singh P.N., Wallender W.W. (2007) Effective Stress from Force Balance on Submerged Granular Particles. Int. J. Geomech., 7: 186-193.

3. Yamamuro J.A., Lade P.V. (1993) B-Value Measurements for Granular Materials at High Confining. Geotech. Test. J., 165-171.

4. Terzaghi K. (1936) The shearing resistance of saturated soils and the angle between planes of shear In: Proc. of Int. Conf. on Smfe. Harvard University.

5. Terzaghi K. (1923) Die berechnung der durchlässigkeitsziffer des tones aus dem verlauf der hydrodynamischen Spannungserscheinungen. Sitzungber Akad Wiss Wien,. 132: 125-138.

6. Skempton A W. (1961) Effective Stress in Soils, Concrete and Rocks. In: Proc. Conf. Pore Pressure \& Suction in Soils. London, UK.

7. OKA F. (1996) Validity and Limits of the Effective Stress Concept in Geomechanics. Mech. Cohesivefrictional. Materials., 219-234.

8. Li G.X. (2007) Can the effective stress principle be overturned. Geot. Eng. World., 10: 22-26.

9. Li G.X. (2011) Some problems about principle of effective stress. Chinese J. Geot. Eng., 33: 315-320.

10. Shao L.T. (2011) Skeleton stress equation for saturated soils. Chinese J. Geot. Eng., 33: 18331837.

11. Lu D.C., Du X.L,. Xu C.S. (2013) Analytical solutions to principle of effective stress. Chinese J. Geot. Eng., 35: 146-151.

12. Biot M A. (1955) Theory of Elasticity and Consolidation for a Porous Anisotropic Solid. J. Appl. Phys., 26: 182-185.

13. Schiffman, Robert L. (1970) The stress components of a porous medium. J. Geophys. Res., 75: 40354038.

14. Skempton A.W., Bishop A.W. (1954) Soils in building materials, their elasticity and inelasticity. North Holland, Amsterdam., 417-482.

15. Bishop A.W. (1959) The Principle of Effective Stress. Teknisk Ukeblad, 39.

16. Cao.Y.C. (2013) Effective Stress Principle of Saturated Soils in Terms of Skeleton Compressibility. Construction Technology., 7-11.

17. Du X.L., Zhang P., Xu C. S., Lu D.C. (2018) Discussion on the effective stress principle and effective stress. Chinese J. Geot. Eng., 40: 486-494.

18. Biot M.A. (1941) General Theory of ThreeDimensional Consolidation. J. Appl. Phys.,12: 155164.

19. Biot M.A., Willis D.G. (1957) The elastic coefficients of the theory of consolidation. J. Appl. Mech., 15: 594-601. 
20. Chen M, Chen Z D. (1999) Effective stress laws for multi-porosity media. Appl. Math. Mech., 11: 12071213.

21. Bishop, A.W. (1973) The influence of an undrained change in stress on the pore pressure in porous media of low compressibility. Geotechnique., 3: 435-442.

22. Zhang Z.C., Cheng X.H. (2014) Effective stress in saturated soil: a granular solid hydrodynamics approach. Granul. Matter, 16: 761-769.

23. Suklje L., Durante V.A. (1971) Rheological Aspects of Soil Mechanics. Hydrotech. Constr., 5: 300-301.

24. Xu C.S., Li Y.M., Pan X., Geng L. (2019) Experimental study on effect of initial static pore water pressure on static and dynamic shear properties of sand. Chinese J. Geot. Eng., 41: 10501057.

25. GB/T 50145 - 2007. (2008) Standard for soil test method. Beijing, M. E. Sharpe. 